\title{
Unusual right internal carotid artery supraclinoid segment fenestration associated with multiple aneurysms treated with flow diversion and coiling
}

\author{
Nihar Jha, ${ }^{1}$ Matthew Thomas Crockett, ${ }^{2}$ Tejinder Pal Singh ${ }^{1}$
}

${ }^{1}$ Sir Charles Gairdner Hospital, Nedlands, Western Australia, Australia

${ }^{2}$ Neurological Imaging and Interventional Sevice of Western Australia, Sir Charles Gairdner Hospital, Nedlands, Western Australia, Australia

\section{Correspondence to} Dr Nihar Jha,

niharjhatn@gmail.com

Accepted 22 August 2018

\section{DESCRIPTION}

The supraclinoid (carotid-ophthalmic) segment of the internal carotid artery (ICA) under the Bouthillier classification is defined as the segment between the ophthalmic and posterior-communicating arteries. ${ }^{1}$ We describe an unusual congenital anomaly of the supraclinoid internal carotid artery characterised by a large fenestration of its carotid-ophthalmic segment, associated with multiple aneurysms.

A 60-year-old female patient underwent investigation for persistent headaches and was found to have what appeared to be irregular fusiform dilatation of the intracranial right internal carotid artery on 1.5 T magnetic resonance angiography (MRA) time-of-flight imaging. Cerebral digital subtraction angiography (DSA) performed to further characterise this abnormality demonstrated two discrete aneurysms, one measuring $5 \mathrm{~mm}$ and the other
$2 \mathrm{~mm}$, arising from the posterior limb of a supraclinoid ICA fenestration (figure 1A).

We proceeded with early endovascular treatment of these aneurysms as the dysplastic ICA vessel combined with its high haemodynamic stress could lead to rapid enlargement of the aneurysms over time. We planned to coil occlude the aneurysm rather than primarily flow divert. This was due to concerns that if flow diversion failed then the aneurysm would be locked out for treatment.

The patient was pre-medicated with aspirin $100 \mathrm{mg}$ daily and clopidogrel $150 \mathrm{mg}$ daily for 7 days with a preoperative platelet reactivity of 141 platelet reactivity units. Following general anaesthesia, an 8 Fr right common femoral artery sheath was inserted under ultrasound guidance and an 8 Fr Neuron MAX Catheter (Penumbra, Alameda, California, USA) was negotiated into
D Check for updates

(c) BMJ Publishing Group Limited 2018. No commercial re-use. See rights and permissions. Published by BMJ.

To cite: Jha N, Crockett MT, Singh TP. BMJ Case Rep Published Online First: [please include Day Month Year]. doi:10.1136/bcr-2018 227020

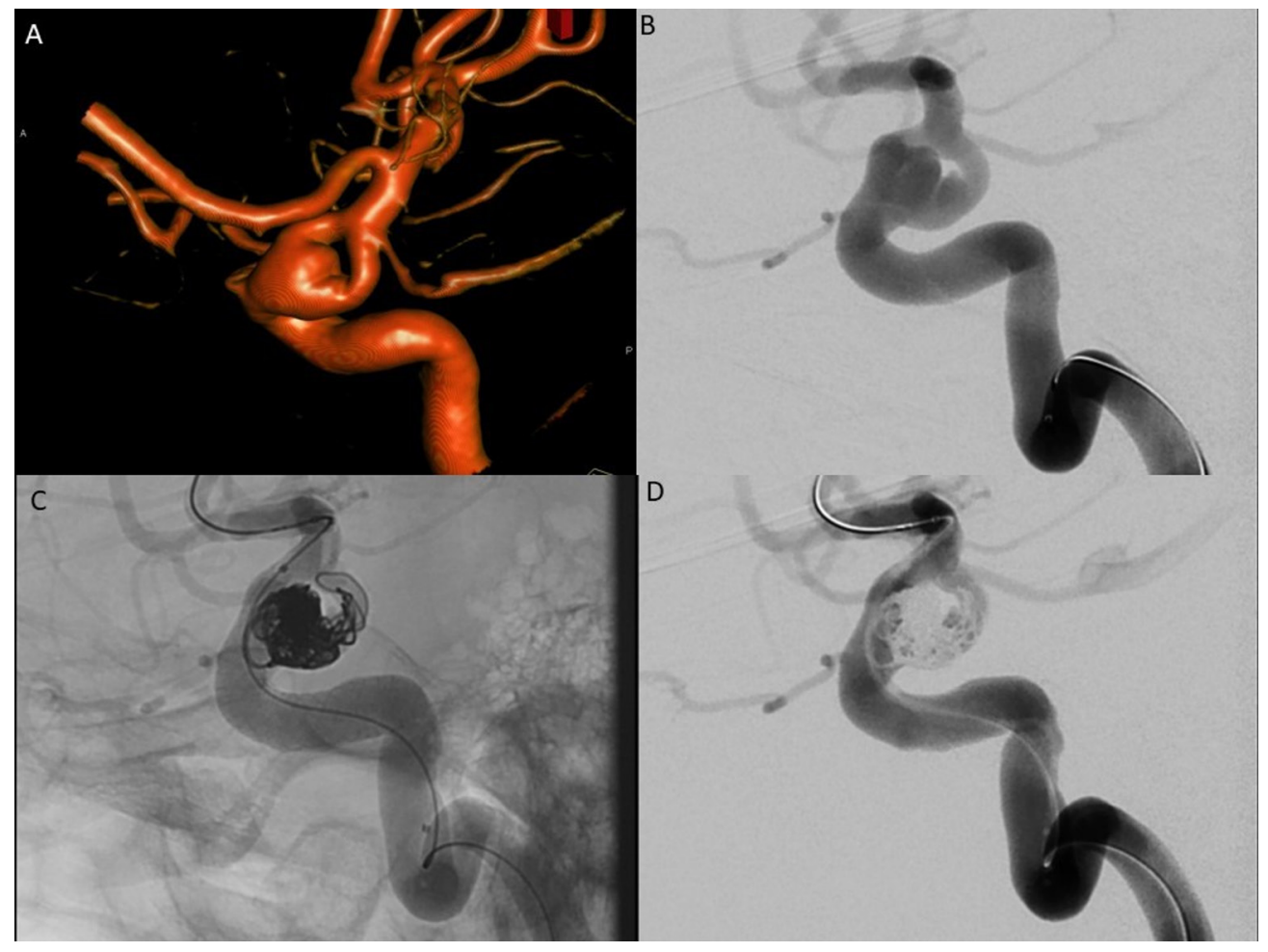

Figure 1 (A) Three-dimensional reconstruction of a rotational digital subtraction angiogram (DSA) demonstrating the supraclinoid right internal carotid artery (ICA) fenestration. Two aneurysms arise from the posterior limb, one measuring $5 \mathrm{~mm}$ between the two limbs and another measuring $2 \mathrm{~mm}$ from the posterior limb. (B) Neuron MAX $8 \mathrm{~F}$ catheter to right ICA. (C) Image showing guidewire, stent placement through the anterior limb and coiling of the interposed aneurysm with some coil in the posterior limb. (D) Final DSA image showing pipeline stent in the anterior limb. 
the petrous segment of the right ICA. Through the Neuron MAX, a Headway Duo micro-catheter (Microvention, Tustin, California, USA) was positioned in the posterior limb of the fenestration and a Marksman micro-catheter (Medtronic, Irvine, California, USA) placed in the proximal M1 segment via the anterior limb (figure 1B). A $4.75 \mathrm{~mm} \times 20 \mathrm{~mm}$ Pipeline stent (Microvention) was deployed into the anterior limb of the fenestration through the Marksman microcatheter jailing the Headway Duo in the aneurysms arising from the posterior limb. $83 \mathrm{~cm}$ of coils (Axium, Medtronic, Irvine, California, USA) were then deployed via the Headway Duo with satisfactory cessation of flow within both aneurysms (figure 1C). Coils were not deployed within the upper segment of the fenestration's posterior limb to preserve the posterior communicating artery (figure 1D). No intraprocedural or postprocedural complications were observed. The patient was discharged on day 2 post procedure and was to continue dual antiplatelet therapy for 6 months.

A fenestration is the segmental separation of a vessel into two channels, with typical intracranial locations being the anterior communicating artery and the anterior cerebral artery. Their aetiology is unknown but thought to related to vasculogenesis and remodelling, with failure of fusion of small vasculogenic vessels. $^{2}$ The limbs of the fenestration are typically dysplastic and are prone to form aneurysms. Supraclinoid ICA fenestrations are extremely rare, with only 20 reported cases since 1984 , and only 3 reports of endovascular management of fenestration associated aneurysms. ${ }^{3}$ This is the third case treated with stent assisted coiling and only the second case to use a flow-diverting stent.

\section{Learning points}

A supraclinoid internal carotid artery fenestration is a rare congenital abnormality that can be associated with aneurysms.

- Effective endovascular treatment of these aneurysms can be undertaken using flow-diverting stents in combination with coil embolisation.

Contributors NJ is the primary author, with substantial contributions from MTC and TPS.

Funding The authors have not declared a specific grant for this research from any funding agency in the public, commercial or not-for-profit sectors.

Competing interests None declared.

Patient consent Obtained.

Provenance and peer review Not commissioned; externally peer reviewed.

\section{REFERENCES}

1 Shapiro M, Becske T, Riina HA, et al. Toward an endovascular internal carotid artery classification system. AJNR Am J Neuroradiol 2014;35:230-6.

2 Dey M, Awad IA. Fenestration of supraclinoid internal carotid artery and associated aneurysm: embryogenesis, recognition, and management. World Neurosurg 2011;76:592.e1-592.e5.

3 Sgreccia A, Coskun O, Di Maria F, et al. Fenestration of the supraclinoid segment of the ICA and associated aneurysms: a case report with literature review. Acta Neurochir 2018;160:1143-7.

Copyright 2018 BMJ Publishing Group. All rights reserved. For permission to reuse any of this content visit http://group.bmj.com/group/rights-licensing/permissions.

BMJ Case Report Fellows may re-use this article for personal use and teaching without any further permission.

Become a Fellow of BMJ Case Reports today and you can:

- Submit as many cases as you like

- Enjoy fast sympathetic peer review and rapid publication of accepted articles

- Access all the published articles

- Re-use any of the published material for personal use and teaching without further permission

For information on Institutional Fellowships contact consortiasales@bmjgroup.com

Visit casereports.bmj.com for more articles like this and to become a Fellow 